\title{
Review of Newly Identified Functions Associated With the Heat-Labile Toxin of Enterotoxigenic Escherichia coli
}

\author{
Qiangde Duan ${ }^{1,2 t}$, Pengpeng Xia ${ }^{1,2 \dagger}$, Rahul Nandre ${ }^{3}$, Weiping Zhang ${ }^{4 *}$ and \\ Guoqiang $\mathrm{Zhu}^{1,2 *}$
}

${ }^{1}$ College of Veterinary Medicine, Institute of Comparative Medicine, Yangzhou University, Yangzhou, China, ${ }^{2}$ Joint International Research Laboratory of Agriculture and Agri-Product Safety of Ministry of Education of China, Jiangsu Co-innovation Center for Prevention and Control of Important Animal Infectious Diseases and Zoonoses, Yangzhou, China, ${ }^{3}$ Department of Microbiology and Immunology, Uniformed Services University, Bethesda, MD, United States, ${ }^{4}$ Department of Pathobiology, University of Illinois at Urbana-Champaign, Urbana, IL, United States

OPEN ACCESS

Edited by:

Vincenzo Scarlato,

University of Bologna, Italy

Reviewed by:

Roberto Mauricio Vidal,

University of Chile, Chile

James Michael Fleckenstein,

Washington University in St. Louis,

United States

*Correspondence:

Weiping Zhang

wpzhang@illinois.edu

Guogiang Zhu

yzgqzhu@yzu.edu.cn

†These authors have contributed equally to this work

Specialty section:

This article was submitted to Molecular Bacterial Pathogenesis,

a section of the journal

Frontiers in Cellular and Infection Microbiology

Received: 20 May 2019

Accepted: 29 July 2019

Published: 13 August 2019

Citation:

Duan Q, Xia P, Nandre R, Zhang W and Zhu G (2019) Review of Newly Identified Functions Associated With

the Heat-Labile Toxin of

Enterotoxigenic Escherichia coli. Front. Cell. Infect. Microbiol. 9:292.

doi: 10.3389/fcimb.2019.00292
Heat-labile toxin $(L T)$ is a well-characterized powerful enterotoxin produced by enterotoxigenic Escherichia coli (ETEC). This toxin is known to contribute to diarrhea in young children in developing countries, international travelers, as well as many different species of young animals. Interestingly, it has also been revealed that LT is involved in other activities in addition to its role in enterotoxicity. Recent studies have indicated that LT toxin enhances enteric pathogen adherence and subsequent intestinal colonization. LT has also been shown to act as a powerful adjuvant capable of upregulating vaccine antigenicity; it also serves as a protein or antigenic peptide display platform for new vaccine development, and can be used as a naturally derived cell targeting and protein delivery tool. This review summarizes the epidemiology, secretion, delivery, and mechanisms of action of LT, while also highlighting new functions revealed by recent studies.

Keywords: LT (heat-labile toxin), ETEC, enterotoxicity, adherence, adjuvanticity

\section{INTRODUCTION}

Enterotoxigenic Escherichia coli (ETEC) is a type of E. coli that is characterized by its ability to produce heat-labile (LT) and/or heat-stable (ST) enterotoxins. ETEC is a leading bacterial cause of diarrhea in children younger than 5 years in developing countries, international travelers, and also neonatal and post-weaning animals (Nagy and Fekete, 2005; World Health Organization, 2006; Crossman et al., 2010; Kotloff et al., 2013; Lamberti et al., 2014; Platts-Mills et al., 2015). ETECinduced diarrhea remains a serious problem with an estimated 840 million infections and over $3,800,000$ deaths worldwide each year. LT is one of the main enterotoxins produced by ETEC (Gupta et al., 2008). LT is categorized as either type I LT (referred to hereafter as LT) or type II LT (LTIIa, b, c) depending on its antigenic capacity and associated genetic sequence (Hajishengallis and Connell, 2013). The amino acid sequences of the LTA subunit of the LT and LTII enterotoxins are highly homologous, whereas, the amino acid sequences of the LTB subunit are highly divergent between LT and LTII (Pickett et al., 1986; Connell, 2007). The A subunit of LT-IIc share 79 and 72\% amino acid sequence homology with the A subunit of LT-IIa and LT-IIb, respectively. However, the B subunit of LT-IIc exhibited only $53 \%$ amino acid sequence similarity to the B subunit 
of LT-IIa and only $54 \%$ amino acid sequence similarity to the B subunit of LT-IIb (Nawar et al., 2010). In addition, LT-IIc exhibits potent immunomodulatory properties that are different from those induced by LT-IIa or LT-IIb (Nawar et al., 2011). While LT-IIa and LT-IIb appear to drive a more balanced Th1/Th2 immune response to a co-administered antigen; LT-IIa or LTIIb, LT-IIc has a greater capacity to drive antigen-specific Th1 type immune responses. Table 1 summarizes differences at the organism, source, and amino acid identity among LT variants, and Table 2 showed their differences at properties. LT can be further categorized into LTh derived from humans and LTp derived from piglets. LT II is predominantly associated with ETEC isolated from animals, while the LT gene is highly prevalent in ETEC strains isolated from both humans and animals. The LT gene was detected in $57.7 \%$ of ETEC isolates associated with porcine post-weaning diarrhea (PWD) in the US (Zhang et al., 2007). In a separate study, it was revealed that approximately $60 \%$ of field ETEC isolates associated with human diarrhea expressed either LT alone (27\%) or LT with ST (33\%) (Isidean et al., 2011). Given the global distribution of LT-specific ETEC strains and the fact that no effective vaccines are currently available, it is likely that infections caused by these pathogens will have a large impact on global public health.

LT holotoxin is initially assembled in the periplasm and then secreted to the outer membrane by one of the following two systems: (1) via the classic type II secretion system (T2SS), (2) through outer membrane vesicles (OMVs) released by ETEC. Even in the presence of the T2SS, a majority of secreted LT remain associated with OMVs because its $\mathrm{B}$ subunits bind lipopolysaccharide (LPS) (Horstman and Kuehn, 2000, 2002). It has been previously been reported that the pentameric LTB subunit structure is required for the effective secretion of the LT holotoxin. It has been suggested that the N-terminal alpha1 helix of LTB is not only required to maintain the structural stability of LT, but is also required for effective binding to GM1 receptors (Alone and Garg, 2008). Recently, Heggelund et al. used surface plasmon resonance spectroscopy to reveal that amino acid residues $7,18,94$, and 95 of the LTB subunit most dramatically affect its binding affinity and specificity (Heggelund et al., 2019). Deletion of the LTB subunit protein affects the secondary structure, impairs its secretion and reduces GM1 receptor affinity. Several LTB subunit mutants were shown to impair the secretion efficiency of LT. The levels of LT secretion are reduced by half among some LTB mutants (Q3K, E11K,

TABLE 1 | Organism, source, and similarity index of variants of LT.

\begin{tabular}{|c|c|c|c|c|}
\hline \multirow[t]{2}{*}{ Variants of LT } & \multirow[t]{2}{*}{ Organism } & \multirow[t]{2}{*}{ Source } & \multicolumn{2}{|c|}{ Similarity index (\%) } \\
\hline & & & LTA subunit & LTB subunit \\
\hline LTh-| & ETEC H10407 & Human & 100 & 100 \\
\hline LTp-I & UMNK88 & Pig & 98.8 & 96.1 \\
\hline LT-Ila & SA53 & Water buffalo & 52.7 & 16.3 \\
\hline LT-IIb & EC41 & Cooked beef & 56.4 & 17.1 \\
\hline LT-IIC & OS-1 & Poultry & 55.9 & 20.7 \\
\hline
\end{tabular}

a The amino acids of LTh was used as the reference when the similarity index was done. and L25E), due to impaired LT secretion (Mudrak et al., 2009; Mudrak and Kuehn, 2010). In addition to the classical type II secretion system, LT can also be secreted through OMVs released by ETEC (Horstman and Kuehn, 2000). It was reported that a vast majority of secreted LT remain attached to the LPS in OMVs on the surface of E. coli (Horstman and Kuehn, 2002). Thus, the delivery of LT is predominantly facilitated by the LT-bound OMVs (internal and external) form, with the 3rd, 11, 46, and 47 residues played an important role in LTB binding to LPS (Mudrak et al., 2009). However, a different study concluded that neither LT nor CT binds to the surface of Vibrio cells, and the disparity may be caused by structure differences in the LPS produced by ETEC and Vibrio (Horstman et al., 2004). The interactions between LT and OMVs as a delivery pathway facilitate an intimate contact between vesicles and the host cells, leading to intoxication. A recent study found that EatA, a serine protease autotransporter of the Enterobacteriaceae (SPATE) protein, can reduce bacterial adhesion and accelerate delivery of the LT by degrading an adhesin called EtpA (Roy et al., 2011). The effective ETEC-host interaction is an essential prerequisite for LT toxin delivery by ETEC. Further, the delivery of LT toxin will enhance ETEC adherence and may increase the receptors of ETEC virulence factors expression. It is important to note that (1) motility, (2) host cell contact (Dorsey et al., 2006), and (3) adhesion (Roy et al., 2012) are each absolute requirements for effective toxin delivery. However, the precise mechanisms that underlie the secretion and delivery of LT remain to be fully elucidated.

LT enterotoxicity has been extensively investigated and is well characterized as shown in Figure 1 (Harford et al., 1989; Tsuji et al., 1990). LT is one of the $A_{1} B_{5}$ toxin family proteins, and is similar in structure, function and pathogenesis to cholera toxin (CT) secreted by Vibrio cholerae (V. cholerae). Briefly, the LTB subunit binds to GM1 receptors with high affinity at the host mucosa surface and enters into epithelial cells via endocytosis. In addition to GM1, LT is capable of binding both blood group $\mathrm{A}$ and $\mathrm{B}$ determinants by interacting with a novel carbohydrate binding site located at the top of the Bsubunit interfaces, distinct from the GM1 binding site (Angström et al., 2000). Following internalization into the endoplasmic reticulum (ER), the LTA peptide is cleaved into A1 and A2 fragments. The ADP-ribosylation activity of the LTA1 fragment activates adenylyl cyclase (AC) thereby elevating intracellular cAMP levels (Gill and Richardson, 1980; Field et al., 1989). Elevated cAMP levels result in the activation of protein kinase A (PKA)-dependent pathways, which inhibits $\mathrm{Na}^{+}$absorption through sodium-hydrogen $\left(\mathrm{Na}^{+} / \mathrm{H}^{+}\right)$exchangers (NHE2 and NHE3) and stimulates $\mathrm{Cl}^{-}$secretion by phosphorylation of the cystic fibrosis transmembrane regulator (CFTR) (Field et al., 1989; Viswanathan et al., 2009). The altered electrolyte and water balance finally lead to severe volumes of watery diarrhea.

\section{LT IMPROVES BACTERIAL ADHERENCE AND INTESTINAL COLONIZATION}

LT contributes to ETEC pathogenesis by facilitating the initial adherence and subsequent intestinal colonization of the murine 
TABLE 2 | Distinct properties of LT and LT-II.

\begin{tabular}{|c|c|c|c|c|c|c|}
\hline & $\begin{array}{c}\text { LTA } \\
\text { (amino acid) }\end{array}$ & $\begin{array}{c}\text { LTB } \\
\text { (amino acid) }\end{array}$ & Cytotoxicity & Receptor(s) & $\begin{array}{l}\text { Th1 or Th2 } \\
\text { response }\end{array}$ & References \\
\hline LTh & 240 & 103 & ++++ & $\begin{array}{l}\text { High: GM1 } \\
\text { Weaker: GM2, GD1b, LPS, A, B-type } \\
\text { blood sugars }\end{array}$ & Th2 & $\begin{array}{l}\text { Fukuta et al., 1988; Horstman and } \\
\text { Kuehn, 2002; Holmner et al., 2007; } \\
\text { Mudrak and Kuehn, } 2010\end{array}$ \\
\hline LTp & 240 & 103 & ++++ & $\begin{array}{l}\text { High: GM1 } \\
\text { Weaker: GM2, GD1b, LPS, A, B-type } \\
\text { blood sugars }\end{array}$ & Th2 & \\
\hline LT-Ila & 241 & 100 & +++ & $\begin{array}{l}\text { High: GD1b } \\
\text { Weaker: GD1a, GM1, GM2, GM3, GT1b, } \\
\text { GQ1b, GD2 }\end{array}$ & Th1 $=$ Th2 & $\begin{array}{l}\text { Fukuta et al., 1988; Hajishengallis } \\
\text { and Connell, } 2013\end{array}$ \\
\hline LT-IIb & 243 & 99 & ++ & $\begin{array}{l}\text { High: GD1a } \\
\text { Weaker: GT1b, GM1b, GD1 } \alpha, \text { GM2, GM3 }\end{array}$ & Th1 $=$ Th2 & $\begin{array}{l}\text { Fukuta et al., 1988; Berenson et al., } \\
\text { 2010; Hajishengallis and Connell, } \\
2013\end{array}$ \\
\hline LT-IIC & 241 & 98 & + & $\begin{array}{l}\text { High: GD1a, GM1, GM2, GM3, GD1 } \alpha \\
\text { Weaker: GQ1b }\end{array}$ & Th1 $>$ Th2 & Nawar et al., 2010, 2011 \\
\hline
\end{tabular}

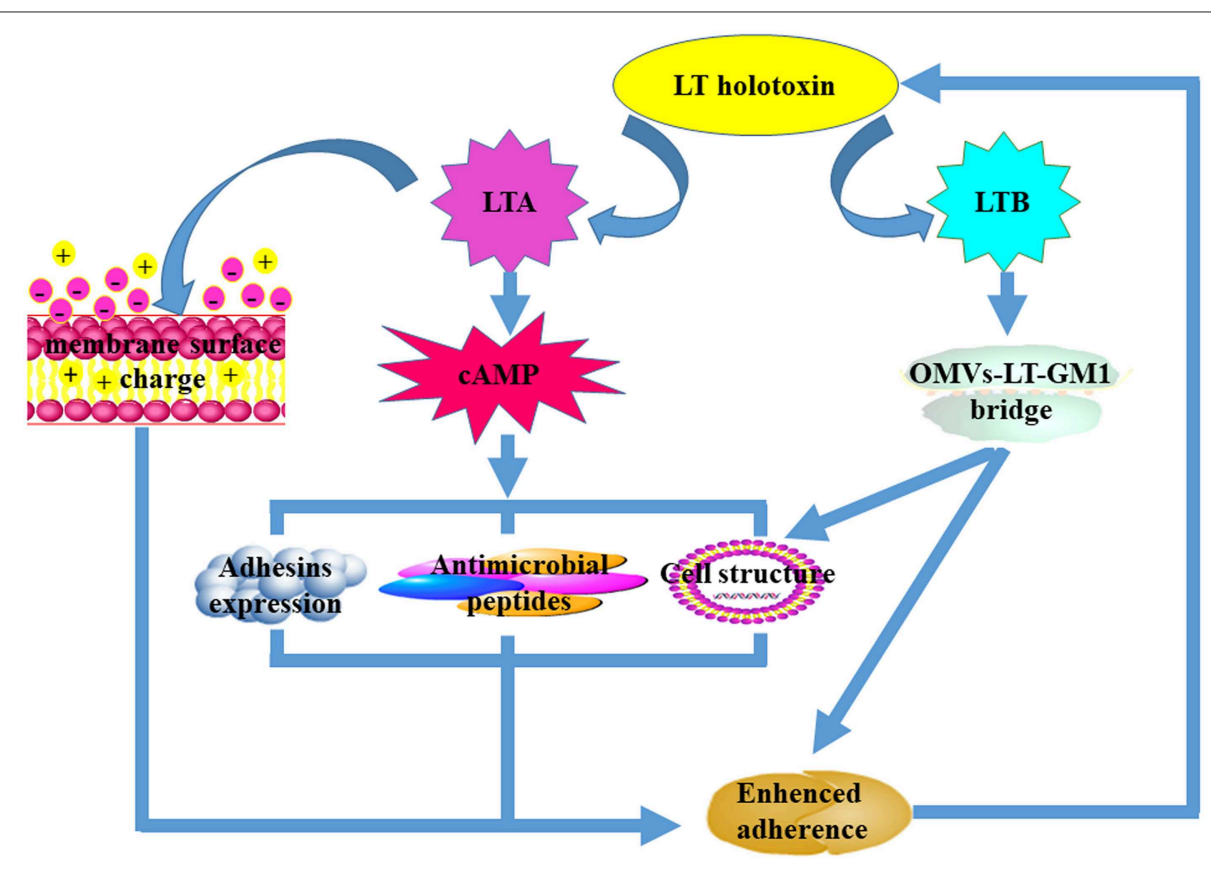

FIGURE 1 | The mechanisms that underpin LT-mediated enhancement of bacterial adherence. Both LTA and LTB subunits are required for LT-mediated enhancement of bacterial adherence. The LTA subunit improves bacterial adherence predominantly by decreasing the cell membrane surface charge and the expression of antimicrobial peptides, increasing the expression of adhesins on the surface, and altering host cell structure. The LTB subunit facilitates bacterial adherence mainly by forming the "OMVs-LT-GM1" bridge after interaction with the GM1 receptors. Alteration of the host cell membrane can also enhance bacterial adherence.

and porcine intestinal mucosa with the subsequent production of watery diarrhea (Berberov et al., 2004; Zhang et al., 2006). The phenomenon of LT-mediated enhancement of bacterial adherence was first observed in a gnotobiotic piglet model of a F4+ ETEC strain infection (Berberov et al., 2004). In this model, a F4+ ETEC mutant unable to produce LT exhibited a dramatic reduction in the colonization of the jejunum and ileum when compared to the wild-type or complementation strain. Likewise, in a separate study, it was reported that expression of F4ac fimbriae, which enable adhesion to small intestine epithelial cells, was significantly increased in a nonpathogenic E. coli field isolate when LT was genetically introduced into the strain (Zhang et al., 2006). Furthermore, similar to the results of a study investigating porcine ETEC infection of gnotobiotic piglets, the former study revealed that elaboration of LT can promote early colonization of human ETEC in a murine model. Subsequently, it was reported that endogenously produced or exogenously added LT substantially enhances the adherence of $\mathrm{K} 88+$ fimbriated ETEC to the cultured piglet epithelial cell line, IPEC-J2 (Johnson et al., 2009). Moreover, expression of LT holotoxin preferentially enhances G58-1 strain adherence compared with expression of the LTB subunit alone; mutants lacking ADP-ribosylation 
enzymatic activity facilitated the same levels of adherence as cells transformed with the LTB subunit construct (Santiago-Mateo et al., 2012; Fekete et al., 2013). In addition, to facilitate ETEC adherence, a recent study revealed that the presence of LT in the gut also significantly promotes Salmonella enterica colonization of pig intestinal cells (Verbrugghe et al., 2015). Up until now, the effect of LT on the enhancement of bacterial adherence has been predominantly studied in enteric pathogens, particularly ETEC strains. However, it is still unclear whether LT also facilitates the other species adherence to host cells. Interestingly, LT has a stronger effect on adherence in F4+ ETEC compared with ETEC carrying other fimbriae.

Although, the intestinal mucus layer forms the first line of host defense against pathogenic microorganisms, it has been reported that LT enhances bacterial adherence by mechanically disrupting the intestinal mucus layer and altering the function of intestinal cells. In addition, LT alters the structure and composition of the intestinal epithelial mucin layer by reducing mucin 4 expression in goblet cells; this phenomenon subsequently leads to bacterial adherence (Verbrugghe et al., 2015). Another study demonstrated that LT can enhance mucin-2 expression and EtpA-dependent ETEC adhesion in vitro. However, it is also reported that the significant numbers of bacteria can adhere to small intestine epithelial cells in MUC2 ${ }^{-/-}$mice than C57BK/6 mice in vivo (Kumar et al., 2016). These results indicated a complex relationship between bacterial adhesion, colonization and LT expression. In addition, LT-mediated inhibition of ascorbic acid uptake (Subramenium et al., 2019) and reduction to the surface charge of the host plasma membrane (Fekete et al., 2013) both affect the function of intestinal cells and promote nonspecific adherence. These phenomena cause interference with the host innate immune response to infection. Human antimicrobial peptides (AMPs) elicit antimicrobial activity against a broad range of enteric pathogens and play critical roles in host innate immune responses. LT was shown to repress the expression of Cathelcidin (LL-37) and B-defensin 1 (HBD-1), thereby facilitating bacterial adherence and subsequent colonization (Chakraborty et al., 2008). In addition to AMPs, LT can also inhibit the expression of pro-inflammatory cytokines including tumor necrosis factor $\alpha$ (TNF- $\alpha)$ and interleukin 8 (IL-8) both of which play important roles in the host innate immune response (Turcanu et al., 2002; Glenn et al., 2009). Finally, LT also enhances adherence by forming an "OMV-LT-GM1" bridge and influencing the expression of other virulence determinants associated with the pathogens. These results indicated that LT-mediated bacterial adherence is mainly attributed to: (1) alteration the structure of intestinal cells; (2) repression of host innate immune responses like inhibiting AMPs and proinflammatory cytokines production; (3) enhancement of the expression of host receptors for adhesins; (4) increase in expression of virulence factors. However, the precise mechanisms that underpin LT-mediated bacterial adherence remain to be elucidated.

It is still unclear which subunit plays a central role in enhancing LT-mediated bacterial adherence. Some studies have suggested that bacterial adherence is enhanced by LT because LT elevates cAMP levels through the ADP-ribosylation activity of the LTA subunit. These studies report that the enhancement of bacterial adherence by LT subverts innate immune responses by blocking host NF- $\kappa$ B activation (Wang and Hardwidge, 2012) and activating the MAPK pathway using cAMP-dependent mechanisms (Johnson et al., 2009; Wang et al., 2012). Given that cAMP is an important secondary messenger in many essential host-signaling pathways, increases in the levels of adherence facilitated by LT appear primarily to be due to increases in the levels of cAMP in host epithelial cells. However, Fekete et al. (2013) reported that both the enzymatic LTA subunit and the adhesive LTB subunit are responsible for LT-enhanced K88+ ETEC adherence to IPEC-J2 cells. In contrast to previous reports, Fekete et al. (2013) suggest that the improved adherence is primarily due to the bridge mediated between the LTB subunit and specific GM1 receptors.

It is now clear that both subunits contribute to LT-enhanced bacterial adherence (Figure 2), even though it remains unclear which subunit plays the central role. LTA contributes to LTenhanced adherence and is mainly dependent on its ADPribosylation activity to facilitate increases in cAMP levels. An elevation in cAMP levels may regulate expression of other bacterial virulence factors and host immune responses. For example, down-regulation of AMPs in the intestine and alterations to the host epithelial cell morphological structure facilitate bacterial adherence to host cells (Yu et al., 2012). An alteration to the surface charge of the host plasma membrane can also increase the levels of non-specific contact between bacteria and host cells. It is likely that the LTB subunit contributes to LT-enhanced adherence by initially forming an "OMV-LT-GM1" bridge to enhance specific binding between bacteria and host cells. After this, it is likely that LTB facilitates LTA subunit internalization into host epithelia after binding to GM1 receptors which are abundant in the lipid rafts of host cells.

\section{LT AS AN ADJUVANT AND ASSOCIATED MECHANISMS OF ACTION}

Although the holotoxin-structured LT molecule is a strong adjuvant, enterotoxicity prevents native LT from being applied clinically. In an attempt to generate nontoxic derivatives of LT that retain significant adjuvanticity, there has been a major focus on reducing or abolishing its ADP-ribosylation activity by substituting the residues of the LTA subunit. The mutant forms of LT that have been generated thus far include a monomeric mutant LT (mLT), a double mutant LT (dmLT), and a triple mutant LT (tmLT) (Okamoto et al., 1988; Tsuji et al., 1990; Douce et al., 1995; Di Tommaso et al., 1996; Giannelli et al., 1997; Kato et al., 1997; Giuliani et al., 1998; Norton et al., 2011; Zhang et al., 2013). The LTS61K mutant was the first mutant generated that was capable of diminishing the toxicity of LT while maintaining the adjuvant properties of the toxin (Harford et al., 1989). Several mLT mutations were also generated; the latter mutants (including R7K, E112K, V53E/D, S63K, A72R, V97K, Y104K/D, S114K/E, R192G, and L211A) focused on reducing the ADP-ribosylation activity of LT (Tsuji et al., 1990; Pizza et al., 


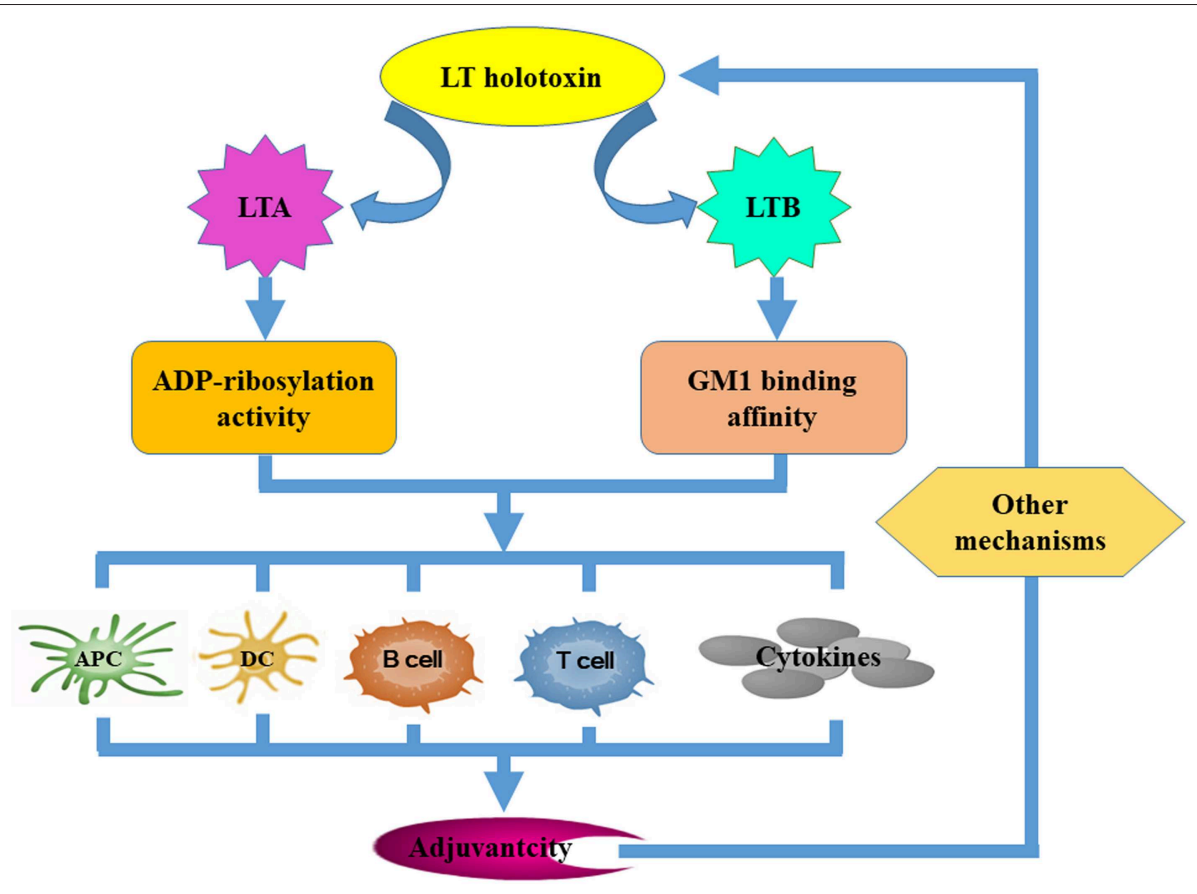

FIGURE 2 | The mechanisms that underpin LT derivative adjuvant activity. Several LT-specific activities facilitate the improvement of vaccine efficacy. Both the ADP-ribosylation activity of the LTA subunit and the GM-binding affinity of the LTB subunit are required for LT to exert its adjuvanticity. Both of these activities contribute to adjuvanticity by improving the antigen-presenting capacity of APCs, promoting DC maturation and activation, activating B and T cells, and inducing cytokine secretion. Other mechanisms independent of the ADP-ribosylation activity of LTA and the GM1-binding affinity of LTB may be required.

1994; Chong et al., 1998; Norton et al., 2011). The prototype of mLT is LTR192G, where a glycine at position 192 was substituted for an arginine. Position 192 is a proteolytically sensitive site in the A-subunit that is essential for separating the A1 and A2 segments. In both in vitro assays and animal studies, mLT shows reduced toxicity and has similar adjuvant activity as the native LT. However, $16.7 \%$ of volunteers develop mild to moderate diarrhea when orally administrated $100 \mu \mathrm{g}$ of LTR192G (Clements and Norton, 2018). In order to further attenuate the enterotoxicity of the mLT mutants, a novel dmLT (LTR192G/L211A) was created by substitution of an alanine for a leucine at amino acid 211 (L211A) of mLT (LTR192G) (Norton et al., 2011). The dmLT mutant resulted in 1,000 times less cAMP in cultured epithelial cells and no detectible fluid accumulation while maintaining immunogenicity and adjuvanticity when compared to the native LT toxin in the patent mouse assay. Research carried out up until now suggests that dmLT is a powerful adjuvant that enhances antigen-specific systemic and mucosal immune responses by parenteral or mucosal immunization (Coleman et al., 2012; Kim et al., 2012; Lee et al., 2014; Norton et al., 2015; Frederick et al., 2018). In our laboratory, we generated a triple mutant LT toxoid [LT (S63K/R192G/L211A), tmLT]; this was fused with three copies of STa toxoid (STaA14Q) to generate the 3 $\times$ STa (A14Q)-tmLT fusion protein (Zhang et al., 2013). The fusion antigen eliminates the capacity to induce cAMP in T84 cells and showed no adverse effects in immunized mice. These results indicate that dmLT or tmLT may represent effective and attractive adjuvants for future vaccines. The characteristics of types of LT mutants used as adjuvants for vaccine were shown in Table 3.

The nontoxic LT or LTB subunits have been used as adjuvants when administrated with a range of antigens (Sjökvist Ottsjö et al., 2013; Nandre and Lee, 2014; Qi et al., 2015) by various routes of administration (Fingerut et al., 2006; Song et al., 2008; Zhang et al., 2009; Nandre et al., 2016; Duan and Zhang, 2017). It has been reported that LT can enhance the immunogenicity of antigens from bacteria, viruses, and fungi thereby improving the efficacy of vaccines (Weltzin et al., 2000; Bonenfant et al., 2001; Romero et al., 2009; Sun et al., 2013; Thiam et al., 2015). The LTS63K and LTR192G mutants are widely used as adjuvants for various candidate vaccines. LTS63K has been demonstrated to act as a potent adjuvant when administrated with Keyhole limpet hemocyanin (KLH) of Bordetella pertussis, foot-andmouth disease virus peptide and colonization factor antigen I (CFA/I) fimbriae of ETEC by the mucosal or parenteral routes (Ryan et al., 2000; Barrette et al., 2011; Byrd and Boedeker, 2013). In our previous study, we demonstrated that when three copies of the STa toxoid mutant were fused to LTR192G, both neutralized anti-STa and anti-LT antibodies were induced in mice that had been immunized with this fusion protein (Zhang et al., 2010; Liu et al., 2011, 2015). dmLT was first developed by Norton and used as an oral adjuvant for tetanus toxoid. Furthermore, dmLT has been shown to be an effective mucosal adjuvant for Helicobacter pylori (H. pylori), IpadB/IpadD of Shigella and poliovirus vaccines (Sjökvist Ottsjö et al., 2013; Lee et al., 2014; White et al., 2014; Norton et al., 2015). 
Although dmLT was first used as a mucosal adjuvant, studies have also revealed the mutant as an effective parenteral adjuvant (Lalsiamthara et al., 2016). It has previously been shown that Salmonella enteritidis live-attenuated vaccines with dmLT as an adjuvant induce robust immune responses (Lalsiamthara et al., 2016). We also demonstrated that ETEC adhesin multi-epitope fusion antigen (MEFA) co-administrated with dmLT elicited strong immune responses to each representative adhesin when administered by either the intraperitoneal (IP) (Duan et al., 2017) or subcutaneous (SC) route (Ruan et al., 2015; Duan and Zhang, 2017). Moreover, induced antibodies inhibited adherence with these adhesins. We also observed that when as little as $0.1 \mu \mathrm{g}$ of the dmLT adjuvant was used, elevated antibody responses were still elicited (unpublished data).

To avoid toxicity, the LTB subunit has been explored for its adjuvanticity when co-administered or fused with antigens. It has reported that LTB subunit expressed in a live attenuated Salmonella enterica Typhimurium strain or transgenic tobacco can used as an mucosal adjuvant to induce mucosal and systemic immune response, and increased the efficacy of the Salmonelladelivered APEC (Chaudhari and Lee, 2013) or transgenic tobacco derived HPV16-L1 vaccine (Hongli et al., 2013). In addition, intranasally vaccinated the enterovirus 71 (EV71) VP1 subunit (EVP1) plus LTB as adjuvant can significantly enhance EVP1 specific systemic and mucosal antibodies. However, intratracheal instillation (IT) of LTB subunit and purified recombinant Ag85A of Mycobacterium tuberculosis induces a Th2-biased immune response, which was generally associated with a poor protection against intracellular mycobacteria when compared to other powerful mucosal adjuvants of the monophosphoryl lipid A of Salmonella minnesota (MPLA) and CpG ODN (Todoroff et al., 2013). These results indicated LTB subunit was not potential adjuvant for pulmonary vaccination. The latter vaccine included a genetic fusion of a target antigen gene with the LTB gene; this was performed by substituting the LTA fragment of the native LT genes with nucleotide fragments coding target antigens to generate a chimeric molecule with a LT-like structure. Using this strategy, the GM1-binding LTB pentamer serves as an adjuvant and also as an antigen carrier to target mucosal immunity. It has been reported when intramuscular (IM) the rabies viruslike particles (VLPs)-LTB fusion protein, rabies virus-specific humoral and cellular immune responses were significantly improved in both mouse and dog models (Qi et al., 2015). Similarly, intranasal and IM with the recombinant chimeric protein containing Mycoplasma hyopneumoniae three antigens (R1, P42, and NrdF) fused to LTB subunit significantly increase a specific immune response in mice and pigs (Marchioro et al., 2014). These results indicated LTB is a potent mucosal and parental adjuvant when co-administrated or fused with a range of antigens.

LT enterotoxicity may preclude clinical implementation of native LT as an adjuvant (or an antigen). However, understanding LT adjuvanticity and associated mechanisms that underpin antigen immuno-regulation can lead to the development of a new generation of nontoxic and effective adjuvants. It is believed that both LT ganglioside-binding and toxic enzyme activities are required to upregulate immune responses (Figure 3). LT displays strong adjuvant effects by improving inflammatory cytokine and chemokine secretion and by transiently recruiting immune effector cells to the site of immunization (Ryan et al., 2000; Pizza et al., 2001). LT is also known to negate adjuvanticity by influencing dendritic cell maturation (Petrovska et al., 2003), antigen presentation (Pitcovski et al., 2006), and B- and T-cell activation (Fu et al., 2009). The LTB subunit modulates host immune responses mainly by (i) improving the antigen-presenting capacity of antigen-presenting cells (APC) using major histocompatibility complex class I (MHC-I) (De Haan et al., 2002) and MHC class II presentation pathways (Nashar et al., 2001; Bone et al., 2002), (ii) influencing the maturation and activation of dendritic cells (DCs) and other APCs (Pitcovski et al., 2006), (iii) eliciting strong humoral and cellular responses by activating both $\mathrm{B}$ and $\mathrm{T}$ lymphocytes, and (iv) stimulating the secretion of cytokines (Yamamoto et al., 2001). It has been reported that the LTB mutant $\mathrm{LTB}_{\mathrm{G} 33 \mathrm{~S}}$ which lacks GM1 receptor-binding activity abolishes any adjuvant ability (Zoeteweij et al., 2006). However, the adjuvant efficacy

TABLE 3 | The characteristic of types of LT mutants as adjuvant.

\begin{tabular}{|c|c|c|c|c|}
\hline Types of LT mutants & Toxicity & Adjuvanticity & Routes of administration & References \\
\hline $\mathrm{mLT}$ & $\begin{array}{l}\text { Very low or completely } \\
\text { defective }\end{array}$ & Strong & Parenteral and mucosal & Ryan et al., 2000; Barrette et al., 2011; Byrd and Boedeker, 2013 \\
\hline $\mathrm{dmLT}$ & Completely defective & Strong & Parenteral and mucosal & Norton et al., 2011, 2015; Lalsiamthara et al., 2016; Duan et al., 2017 \\
\hline tmLT & Completely defective & Strong & Parenteral and mucosal & Zhang et al., 2013 \\
\hline
\end{tabular}

\begin{tabular}{|l|l|l|l|l|l|l|l|l|l|l|l|l||l|l||l|l|}
\hline e1 & e2 & e3 & & e4 & e5 & LTA1 & e6 & LTA1 & e7 & & e8 & e9 & e10 & e11 & LTA2 \\
\hline
\end{tabular}

FIGURE 3 | The mapping of epitopes of LTA1 segment. LTA subunit continuous B-cell epitopes were in silico identified by using web-based B-cell epitope software as previously described (Ruan et al., 2015). In total, 11 epitopes were identified, the amino acid sequence and position of each epitope is: e1 (1-11): NGDKLYRADSR, e2 (9-21): DSRPPDEIKRSGG, e3 (25-36): RGHNEYFDRGTQ, e4 (42-51): YDHARGTQTG, e5 (54-63): RYDDG YVSTS, e6 (105-115): SPHPYEQEVSA, e7 (140-149): HRNREYRDRY, e8 (156-166): APAEDGYRLAG, e9 (165-177): AGFPPDHQAWREE, e10 (181-193): HHAPQGCGNSSRT, e11 (193-204): TITGDTCNEETQ. The LTA1 segment is gray, LTA2 is green, and the overlap sequence between e1 and e2, e8 and e9, e9 and e10 is blue. 
of mutant $\mathrm{LTB}_{\mathrm{H} 57 \mathrm{~S}}$ which maintains $\mathrm{GM} 1$ receptor-binding ability was abolished (Aman et al., 2001). This may suggest that binding to the GM1 receptor is necessary but is not the only mechanism that underlies LTB adjuvant activity. LTA subunit adjuvanticity is predominantly related to its ability to elevate intracellular cAMP. However, the requirement for LTA subunit ADP-ribosylation activity in relation to its adjuvanticity is not well defined. Some catalytically defective and non-toxic LTA mutants still retain strong adjuvant activity (Pizza et al., 1994; Dickinson and Clements, 1995; Douce et al., 1998; Ma, 2016), suggesting that neither induction of cAMP nor enzymatic activity are essential for adjuvant activity. In contrast, Larena et al. (2015) reported that a LT double mutant, which is considered non-toxic induces minimal cAMP production but abrogates its adjuvant effects, indicating that ADP-ribosylation activity is necessary for the adjuvant activities of the LTA subunit. Norton et al. (2012) demonstrated that the LTA subunit alone independent from the $A_{1} B_{5}$ holotoxin structure or the presence of the LTB subunit possesses adjuvant activity; whereas de Haan et al. (1998) suggested that the adjuvant activity of non-toxic LTA in combination with the LTB pentamer may be stronger than that of LTA or the LTB subunit alone. Other mechanisms independent of LTA ADP-ribosylation activity or LTB GM1-binding affinity may also exist. The TLR-dependent signaling pathway (Hajishengallis et al., 2005; Hajishengallis and Connell, 2013) along with the Nod2-mediated recognition of the microbiota (Kim et al., 2016) could also be involved in LT adjuvant activity. Additionally, routes of immunization, LT-antigen combinations (whether administered as mixtures, fusion constructs or through chemical coupling) and antigen doses also effect LT adjuvanticity.

\section{LT AS A CARRIER OR INTRACELLULAR TRAFFICKING VEHICLE IN ADVANCED THERAPIES}

Within the LT family, the LA1 toxic segment is dispensable for co-assembly of the A2 segment with the LTB subunit, thus making it possible that this segment could be used as a platform to display vaccine antigen epitopes. Indeed, Ruan and Zhang (2013) demonstrated that a triple LT mutant (LTS63K/R192G/L211A), which had LT segments replaced by the porcine ETEC adhesin K88 major FaeG subunit and F18 minor FedF subunit domains, not only formed the $A_{1} B_{5}$ holotoxin structure and bound GM1 receptors but also induced antigenspecific protective mucosal immunity against $\mathrm{K} 88+$ and F18+ ETEC. Recently, Huang et al. (2018) mapped 11 epitopes of the $\mathrm{LTA}_{1}$ domain (Figure 3) and showed that LT with each individual epitope substituted with a foreign epitope exhibited no enterotoxicity but retained $\mathrm{GM}_{1}$-binding activity. These results suggest that LT can be potentially used as a novel platform to display heterogeneous epitopes for multivalent vaccines against ETEC and other pathogens.

Biologic therapeutics involves novel medical therapeutic strategies based on the delivery of functional proteins to biochemically relevant sites within diseased cells. Although there has been a rapid increase in clinical biologics, the main challenge pertains to the lack of suitable intracellular trafficking vehicles to deliver active biologic drugs to targeted cells. LT can be used as a novel intracellular trafficking vehicle due to its specific ADPribosylation catalytic functionality and cell binding specificity. Liu et al. (2016) demonstrated that the LTA2 segment of the LTA subunit is alone capable of penetrating intestinal and cancer cell membranes. The LTA2 domain together with a fused fluorescent protein can be transported into cells by an $\mathrm{A} 2$ domain-mediated transmembrane transporting process similar to a cell-penetrating peptide (CPP). Recently, Lichtenstein and Hocker identified the requisite sequence and associated structures of LTA2 required for the efficient and stable co-assembly of protein cargo with the nontoxic LTB subunit (Lichtenstein and Höcker, 2018). These results suggest that the LT toxin or the LTA2 domain of LTA alone could be used as an intracellular trafficking vehicle for the delivery of biologically active proteins and drugs into cells; in the future, these strategies might be exploited for the treatment of cancer.

\section{CONCLUSION}

It is noteworthy that recent evidence indicates that LT harbors functions beyond enterotoxic activity. LT also plays a significant role in the enhancement of bacterial adherence, the modulation of immune responses, and the delivery of fused foreign antigens. Recently, LT has been reported to trigger reductions in intestinal epithelial cell viability and to induce apoptosis in a doseand time-dependent manner in human intestine cell lines ( $\mathrm{Lu}$ et al., 2017). We expect that additional functions of LT will be unearthed in future studies. While these studies certainly advance our understanding of LT-mediated activities, other questions remain unanswered. For instance, it will be interesting to see whether other pathways, apart from the cAMP signaling pathway, are involved in LT-mediated diarrhea. While LTA and LTB subunits are required to enhance bacterial adherence and adjuvant activities collectively, the precise contribution from individual subunits and detailed mechanisms that underlie these activities remain to be defined. It would appear that binding of the ganglioside GM1 is an essential feature in the facilitation of LT adjuvant properties. It remains to be seen whether other gangliosides (like GD1b, asialo GM1, GM2, and GM3) also participate in the requisite molecular and cellular events that promote adjuvanticity. It will also be interesting to investigate whether Toll-like receptors (TLRs) are involved in LT adjuvant activity due to LT-IIb-B5 pentamer was reported to has ability to activate the TLR2/TLR1 heterodimer and induce NF- $\mathrm{KB}$ dependent production of proinflammatory cytokines (Liang et al., 2007, 2009). Recently, Nod2-mediated recognition of the microbiota was observed to be critical for cholera toxin mucosal adjuvanticity; however, whether LT utilizes the same pathway to elicit mucosal adjuvanticity has not yet been confirmed. Further studies are required to better understand LT bioactivities and to gain a greater insight into the molecular mechanisms pertaining to this important toxin in ETEC pathogenicity.

\section{AUTHOR CONTRIBUTIONS}

GZ and WZ designed the structure of the review. QD drafted the manuscript. PX prepared the figures. GZ, RN, and WZ critically revised the manuscript. 


\section{FUNDING}

This study was supported by grants from the Chinese National Science Foundation (Grant Nos. 31800121, 31873010, 31702242, and 31672579) and the 63rd China Postdoctoral Science Foundation, grants from High-level Talents of

\section{REFERENCES}

Alone, P. V., and Garg, L. C. (2008). Secretory and GM1 receptor binding role of $\mathrm{N}$-terminal region of LTB in Vibrio cholerae. Biochem. Biophys. Res. Commun. 376, 770-774. doi: 10.1016/j.bbrc.2008.09.066

Aman, A. T., Fraser, S., Merritt, E. A., Rodigherio, C., Kenny, M., Ahn, M., et al. (2001). A mutant cholera toxin B subunit that binds GM1-ganglioside but lacks immunomodulatory or toxic activity. Proc. Natl. Acad. Sci. U.S.A. 98, 8536-8541. doi: 10.1073/pnas.161273098

Angström, J., Bäckström, M., Berntsson, A., Karlsson, N., Holmgren, J., Karlsson, K. A., et al. (2000). Novel carbohydrate binding site recognizing blood group A and B determinants in a hybrid of cholera toxin and Escherichia coli heat-labile enterotoxin B-subunits. J. Biol. Chem. 275, 3231-3238. doi: $10.1074 /$ jbc.275.5.3231

Barrette, R. W., Szczepanek, S. M., Rood, D., Challa, S., Avery, N., Vajdy, M., et al. (2011). Use of inactivated Escherichia coli enterotoxins to enhance respiratory mucosal adjuvanticity during vaccination in swine. Clin. Vaccine Immunol. 18, 1996-1998. doi: 10.1128/CVI.05273-11

Berberov, E. M., Zhou, Y., Francis, D. H., Scott, M. A., Kachman, S. D., and Moxley, R. A. (2004). Relative importance of heat-labile enterotoxin in the causation of severe diarrheal disease in the gnotobiotic piglet model by a strain of enterotoxigenic Escherichia coli that produces multiple enterotoxins. Infect. Immun. 72, 3914-3924. doi: 10.1128/IAI.72.7.3914-3924.2004

Berenson, C. S., Nawar, H. F., Yohe, H. C., Castle, S. A., Ashline, D. J., Reinhold, V. N., et al. (2010). Mammalian cell ganglioside-binding specificities of $E$. coli enterotoxins LT-IIb and variant LT-IIb(T13I). Glycobiology 20, 41-54. doi: 10.1093/glycob/cwp141

Bone, H., Eckholdt, S., and Williams, N. A. (2002). Modulation of B lymphocyte signalling by the B subunit of Escherichia coli heat-labile enterotoxin. Int. Immunol. 14, 647-658. doi: 10.1093/intimm/dxf029

Bonenfant, C., Dimier-Poisson, I., Velge-Roussel, F., Buzoni-Gatel, D., Del Giudice, G., Rappuoli, R., et al. (2001). Intranasal immunization with SAG1 and nontoxic mutant heat-labile enterotoxins protects mice against Toxoplasma gondii. Infect. Immun. 69, 1605-1612. doi: 10.1128/IAI.69.3.1605-16 12.2001

Byrd, W., and Boedeker, E. C. (2013). Attenuated Escherichia coli strains expressing the colonization factor antigen I (CFA/I) and a detoxified heatlabile enterotoxin (LThK63) enhance clearance of ETEC from the lungs of mice and protect mice from intestinal ETEC colonization and LTinduced fluid accumulation. Vet. Immunol. Immunopathol. 152, 57-67. doi: 10.1016/j.vetimm.2012.10.001

Chakraborty, K., Ghosh, S., Koley, H., Mukhopadhyay, A. K., Ramamurthy, T., Saha, D. R., et al. (2008). Bacterial exotoxins downregulate cathelicidin (hCAP-18/LL-37) and human beta-defensin 1 (HBD-1) expression in the intestinal epithelial cells. Cell. Microbiol. 10, 2520-2537. doi: 10.1111/j.1462-5822.2008.01227.x

Chaudhari, A. A., and Lee, J. H. (2013). Evaluation of the adjuvant effect of Salmonella-based Escherichia coli heat-labile toxin B subunits on the efficacy of a live Salmonella-delivered avian pathogenic Escherichia coli vaccine. Avian Pathol. 42, 365-372. doi: 10.1080/03079457.2013.811466

Chong, C., Friberg, M., and Clements, J. D. (1998). LT(R192G), a nontoxic mutant of the heat-labile enterotoxin of Escherichia coli, elicits enhanced humoral and cellular immune responses associated with protection against lethal oral challenge with Salmonella spp. Vaccine 16, 732-740. doi: 10.1016/S0264-410X(97)00255-7

Clements, J. D., and Norton, E. B. (2018). The mucosal vaccine adjuvant LT(R192G/L211A) or dmLT. mSphere 3:e0215-18. doi: $10.1128 / \mathrm{mSphere} .00215-18$
Yangzhou University Scientific Research Foundation, a project founded by the Priority Academic Program of Development Jiangsu High Education Institution. The project was also supported by grants from the Yangzhou Science and Technology Bureau International Cooperation Project (YZ2018154).
Coleman, B. L., McGeer, A. J., Halperin, S. A., Langley, J. M., Shamout, Y., Taddio, A., et al. (2012). A randomized control trial comparing immunogenicity, safety, and preference for self- versus nurse-administered intradermal influenza vaccine. Vaccine 30, 6287-6293. doi: 10.1016/j.vaccine.2012.08.006

Connell, T. D. (2007). Cholera toxin, LT-I, LT-IIa and LT-IIb: the critical role of ganglioside binding in immunomodulation by type I and type II heat-labile enterotoxins. Expert Rev. Vaccines 6, 821-834. doi: 10.1586/14760584.6.5.821

Crossman, L. C., Chaudhuri, R. R., Beatson, S. A., Wells, T. J., Desvaux, M., Cunningham, A. F., et al. (2010). A commensal gone bad: complete genome sequence of the prototypical enterotoxigenic Escherichia coli strain H10407. J. Bacteriol. 192, 5822-5831. doi: 10.1128/JB.00710-10

De Haan, L., Hearn, A. R., Rivett, A. J., and Hirst, T. R. (2002). Enhanced delivery of exogenous peptides into the class I antigen processing and presentation pathway. Infect. Immun. 70, 3249-3258. doi: 10.1128/IAI.70.6.3249-3258.2002

de Haan, L., Verweij, W. R., Feil, I. K., Holtrop, M., Hol, W. G., Agsteribbe, E., et al. (1998). Role of GM1 binding in the mucosal immunogenicity and adjuvant activity of the Escherichia coli heat-labile enterotoxin and its B subunit. Immunology 94, 424-430. doi: 10.1046/j.1365-2567.1998.00535.x

Di Tommaso, A., Saletti, G., Pizza, M., Rappuoli, R., Dougan, G., Abrignani, S., et al. (1996). Induction of antigen-specific antibodies in vaginal secretions by using a nontoxic mutant of heat-labile enterotoxin as a mucosal adjuvant. Infect. Immun. 64, 974-979.

Dickinson, B. L., and Clements, J. D. (1995). Dissociation of Escherichia coli heatlabile enterotoxin adjuvanticity from ADP-ribosyltransferase activity. Infect. Immun. 63, 1617-1623.

Dorsey, F. C., Fischer, J. F., and Fleckenstein, J. M. (2006). Directed delivery of heat-labile enterotoxin by enterotoxigenic Escherichia coli. Cell. Microbiol. 8, 1516-1527. doi: 10.1111/j.1462-5822.2006.00736.x

Douce, G., Giuliani, M. M., Giannelli, V., Pizza, M. G., Rappuoli, R., and Dougan, G. (1998). Mucosal immunogenicity of genetically detoxified derivatives of heat labile toxin from Escherichia coli. Vaccine 16, 1065-1073. doi: 10.1016/S0264-410X(98)80100-X

Douce, G., Turcotte, C., Cropley, I., Roberts, M., Pizza, M., Domenghini, M., et al. (1995). Mutants of Escherichia coli heat-labile toxin lacking ADPribosyltransferase activity act as nontoxic, mucosal adjuvants. Proc. Natl. Acad. Sci. U.S.A. 92, 1644-1648. doi: 10.1073/pnas.92.5.1644

Duan, Q., Lee, K. H., Nandre, R. M., Garcia, C., Chen, J., and Zhang, W. (2017). MEFA (multiepitope fusion antigen)-novel technology for structural vaccinology, proof from computational and empirical immunogenicity characterization of an enterotoxigenic Escherichia coli (ETEC) adhesin MEFA. J. Vaccines Vaccin. 8:367. doi: 10.4172/2157-7560.1000367

Duan, Q., and Zhang, W. (2017). Genetic fusion protein 3xSTa-ovalbumin is an effective coating antigen in ELISA to titrate anti-STa antibodies. Microbiol. Immunol. 61, 251-257. doi: 10.1111/1348-0421.12494

Fekete, P. Z., Mateo, K. S., Zhang, W., Moxley, R. A., Kaushik, R. S., and Francis, D. H. (2013). Both enzymatic and non-enzymatic properties of heat-labile enterotoxin are responsible for LT-enhanced adherence of enterotoxigenic Escherichia coli to porcine IPEC-J2 cells. Vet. Microbiol. 164, 330-335. doi: 10.1016/j.vetmic.2013.02.019

Field, M., Rao, M. C., and Chang, E. B. (1989). Intestinal electrolyte transport and diarrheal disease (2). N. Engl. J. Med. 321, 879-883. doi: 10.1056/NEJM198909283211307

Fingerut, E., Gutter, B., Goldway, M., Eliahoo, D., and Pitcovski, J. (2006). B subunit of E. coli enterotoxin as adjuvant and carrier in oral and skin vaccination. Vet. Immunol. Immunopathol. 112, 253-263. doi: 10.1016/j.vetimm.2006.03.005

Frederick, D. R., Goggins, J. A., Sabbagh, L. M., Freytag, L. C., Clements, J. D., and McLachlan, J. B. (2018). Adjuvant selection regulates gut migration and 
phenotypic diversity of antigen-specific $\mathrm{CD} 4(+) \mathrm{T}$ cells following parenteral immunization. Mucosal Immunol. 11, 549-561. doi: 10.1038/mi.2017.70

Fu, N., Khan, S., Quinten, E., de Graaf, N., Pemberton, A. J., Rivett, A. J., et al. (2009). Effective CD8(+) T cell priming and tumor protection by enterotoxin B subunit-conjugated peptides targeted to dendritic cells. Vaccine 27, 5252-5258. doi: 10.1016/j.vaccine.2009.06.053

Fukuta, S., Magnani, J. L., Twiddy, E. M., Holmes, R. K., and Ginsburg, V. (1988). Comparison of the carbohydrate-binding specificities of cholera toxin and Escherichia coli heat-labile enterotoxins LTh-I, LT-IIa, and LT-IIb. Infect. Immun. 56, 1748-1753.

Giannelli, V., Fontana, M. R., Giuliani, M. M., Guangcai, D., Rappuoli, R., and Pizza, M. (1997). Protease susceptibility and toxicity of heat-labile enterotoxins with a mutation in the active site or in the protease-sensitive loop. Infect. Immun. 65, 331-334.

Gill, D. M., and Richardson, S. H. (1980). Adenosine diphosphateribosylation of adenylate cyclase catalyzed by heat-labile enterotoxin of Escherichia coli: comparison with cholera toxin. J. Infect. Dis. 141, 64-70. doi: 10.1093/infdis/141.1.64

Giuliani, M. M., Del Giudice, G., Giannelli, V., Dougan, G., Douce, G., Rappuoli, R., et al. (1998). Mucosal adjuvanticity and immunogenicity of LTR72, a novel mutant of Escherichia coli heat-labile enterotoxin with partial knockout of ADP-ribosyltransferase activity. J. Exp. Med. 187, 1123-1132. doi: 10.1084/jem.187.7.1123

Glenn, G. M., Francis, D. H., and Danielsen, E. M. (2009). Toxin-mediated effects on the innate mucosal defenses: implications for enteric vaccines. Infect. Immun. 77, 5206-5215. doi: 10.1128/IAI.00712-09

Gupta, S. K., Keck, J., Ram, P. K., Crump, J. A., Miller, M. A., and Mintz, E. D. (2008). Part III. Analysis of data gaps pertaining to enterotoxigenic Escherichia coli infections in low and medium human development index countries, 19842005. Epidemiol. Infect. 136, 721-738. doi: 10.1017/S095026880700934X

Hajishengallis, G., and Connell, T. D. (2013). Type II heat-labile enterotoxins: structure, function, and immunomodulatory properties. Vet. Immunol. Immunopathol. 152, 68-77. doi: 10.1016/j.vetimm.2012.09.034

Hajishengallis, G., Tapping, R. I., Martin, M. H., Nawar, H., Lyle, E. A., Russell, M. W., et al. (2005). Toll-like receptor 2 mediates cellular activation by the B subunits of type II heat-labile enterotoxins. Infect. Immun. 73, 1343-1349. doi: 10.1128/IAI.73.3.1343-1349.2005

Harford, S., Dykes, C. W., Hobden, A. N., Read, M. J., and Halliday, I. J. (1989). Inactivation of the Escherichia coli heat-labile enterotoxin by in vitro mutagenesis of the A-subunit gene. Eur. J. Biochem. 183, 311-316. doi: 10.1111/j.1432-1033.1989.tb14930.x

Heggelund, J. E., Heim, J. B., Bajc, G., Hodnik, V., Anderluh, G., and Krengel, U. (2019). Specificity of Escherichia coli heat-labile enterotoxin investigated by single-site mutagenesis and crystallography. Int. J. Mol. Sci. 20:E703. doi: $10.3390 /$ ijms 20030703

Holmner, A., Askarieh, G., Okvist, M., and Krengel, U. (2007). Blood group antigen recognition by Escherichia coli heat-labile enterotoxin. J. Mol. Biol. 371, 754-764. doi: 10.1016/j.jmb.2007.05.064

Hongli, L., Xukui, L., Ting, L., Wensheng, L., Lusheng, S., and Jin, Z. (2013). Transgenic tobacco expressed HPV16-L1 and LT-B combined immunization induces strong mucosal and systemic immune responses in mice. Hum. Vaccin. Immunother. 9, 83-89. doi: 10.4161/hv.22292

Horstman, A. L., Bauman, S. J., and Kuehn, M. J. (2004). Lipopolysaccharide 3deoxy-D-manno-octulosonic acid (Kdo) core determines bacterial association of secreted toxins. J. Biol. Chem. 279, 8070-8075. doi: 10.1074/jbc.M308 633200

Horstman, A. L., and Kuehn, M. J. (2000). Enterotoxigenic Escherichia coli secretes active heat-labile enterotoxin via outer membrane vesicles. J. Biol. Chem. 275, 12489-12496. doi: 10.1074/jbc.275.17.12489

Horstman, A. L., and Kuehn, M. J. (2002). Bacterial surface association of heat-labile enterotoxin through lipopolysaccharide after secretion via the general secretory pathway. J. Biol. Chem. 277, 32538-32545. doi: 10.1074/jbc.M203740200

Huang, J., Duan, Q., and Zhang, W. (2018). Significance of Enterotoxigenic Escherichia coli (ETEC) heat-labile toxin (LT) enzymatic subunit epitopes in LT enterotoxicity and immunogenicity. Appl. Environ. Microbiol. 84:e00849-18. doi: 10.1128/AEM.00849-18
Isidean, S. D., Riddle, M. S., Savarino, S. J., and Porter, C. K. (2011). A systematic review of ETEC epidemiology focusing on colonization factor and toxin expression. Vaccine 29, 6167-6178. doi: 10.1016/j.vaccine.2011.06.084

Johnson, A. M., Kaushik, R. S., Francis, D. H., Fleckenstein, J. M., and Hardwidge, P. R. (2009). Heat-labile enterotoxin promotes Escherichia coli adherence to intestinal epithelial cells. J. Bacteriol. 191, 178-186. doi: 10.1128/JB.00822-08

Kato, M., Imamura, S., Kawase, H., Miyama, A., and Tsuji, T. (1997). Histidine44 of the A subunit of Escherichia coli enterotoxin is involved in its enzymatic and biological activities. FEMS Microbiol. Lett. 152, 219-225. doi: 10.1111/j.1574-6968.1997.tb10431.x

Kim, D., Kim, Y. G., Seo, S. U., Kim, D. J., Kamada, N., Prescott, D., et al. (2016). Nod2-mediated recognition of the microbiota is critical for mucosal adjuvant activity of cholera toxin. Nat. Med. 22, 524-530. doi: 10.1038/nm.4075

Kim, Y. C., Jarrahian, C., Zehrung, D., Mitragotri, S., and Prausnitz, M. R. (2012). Delivery systems for intradermal vaccination. Curr. Top. Microbiol. Immunol. 351, 77-112. doi: 10.1007/82_2011_123

Kotloff, K. L., Nataro, J. P., Blackwelder, W. C., Nasrin, D., Farag, T. H., Panchalingam, S., et al. (2013). Burden and aetiology of diarrhoeal disease in infants and young children in developing countries (the Global Enteric Multicenter Study, GEMS): a prospective, case-control study. Lancet 382, 209-222. doi: 10.1016/S0140-6736(13)60844-2

Kumar, P., Kuhlmann, F. M., Bhullar, K., Yang, H., Vallance, B. A., Xia, L., et al. (2016). Dynamic interactions of a conserved enterotoxigenic Escherichia coli adhesin with intestinal mucins govern epithelium engagement and toxin delivery. Infect. Immun. 84, 3608-3617. doi: 10.1128/IAI.00692-16

Lalsiamthara, J., Kamble, N. M., and Lee, J. H. (2016). A live attenuated Salmonella enteritidis secreting detoxified heat labile toxin enhances mucosal immunity and confers protection against wild-type challenge in chickens. Vet. Res. 47:60. doi: 10.1186/s13567-016-0348-7

Lamberti, L. M., Bourgeois, A. L., Fischer Walker, C. L., Black, R. E., and Sack, D. (2014). Estimating diarrheal illness and deaths attributable to Shigellae and enterotoxigenic Escherichia coli among older children, adolescents, and adults in South Asia and Africa. PLoS Negl. Trop. Dis. 8:e2705. doi: 10.1371/journal.pntd.0002705

Larena, M., Holmgren, J., Lebens, M., Terrinoni, M., and Lundgren, A. (2015). Cholera toxin, and the related nontoxic adjuvants mmCT and dmLT, promote human Th17 responses via cyclic AMP-protein kinase A and inflammasome-dependent IL-1 signaling. J. Immunol. 194, 3829-3839. doi: 10.4049/jimmunol.1401633

Lee, S., Picking, W. L., and Tzipori, S. (2014). The immune response of two microbial antigens delivered intradermally, sublingually, or the combination thereof. Microbes Infect. 16, 796-803. doi: 10.1016/j.micinf.2014.07.013

Liang, S., Hosur, K. B., Lu, S., Nawar, H. F., Weber, B. R., Tapping, R. I., et al. (2009). Mapping of a microbial protein domain involved in binding and activation of the TLR2/TLR1 heterodimer. J. Immunol. 182, 2978-2985. doi: 10.4049/jimmunol.0803737

Liang, S., Wang, M., Triantafilou, K., Triantafilou, M., Nawar, H. F., Russell, M. W., et al. (2007). The A subunit of type IIb enterotoxin (LT-IIb) suppresses the proinflammatory potential of the B subunit and its ability to recruit and interact with TLR2. J. Immunol. 178, 4811-4819. doi: 10.4049/jimmunol.178.8.4811

Lichtenstein, B. R., and Höcker, B. (2018). Engineering an AB5 protein carrier. Sci. Rep. 8:12643. doi: 10.1038/s41598-018-30910-y

Liu, D., Guo, H., Zheng, W., Zhang, N., Wang, T., Wang, P., et al. (2016). Discovery of the cell-penetrating function of A2 domain derived from LTA subunit of Escherichia coli heat-labile enterotoxin. Appl. Microbiol. Biotechnol. 100, 5079-5088. doi: 10.1007/s00253-016-7423-x

Liu, M., Zhang, C., Mateo, K., Nataro, J. P., Robertson, D. C., and Zhang, W. (2011). Modified heat-stable toxins (hSTa) of enterotoxigenic Escherichia coli lose toxicity but display antigenicity after being genetically fused to heat-labile toxoid LT(R192G). Toxins (Basel) 3, 1146-1162. doi: 10.3390/toxins3091146

Liu, W., Yuan, C., Bao, J., Guan, W., Zhao, Z., Li, X., et al. (2015). Generation of an attenuated strain oral vaccine candidate using a novel double selection platform in Escherichia coli. Appl. Microbiol. Biotechnol. 99, 855-867. doi: 10.1007/s00253-014-6099-3

Lu, X., Li, C., Li, C., Li, P., Fu, E., Xie, Y., et al. (2017). Heat-labile enterotoxininduced PERK-CHOP pathway activation causes intestinal epithelial cell apoptosis. Front. Cell. Infect. Microbiol. 7:244. doi: 10.3389/fcimb.2017.00244 
Ma, Y. (2016). Recent advances in nontoxic Escherichia coli heat-labile toxin and its derivative adjuvants. Expert Rev. Vaccines 15, 1361-1371. doi: 10.1080/14760584.2016.1182868

Marchioro, S. B., Fisch, A., Gomes, C. K., Jorge, S., Galli, V., Haesebrouck, F., et al. (2014). Local and systemic immune responses induced by a recombinant chimeric protein containing Mycoplasma hyopneumoniae antigens fused to the B subunit of Escherichia coli heat-labile enterotoxin LTB. Vet. Microbiol. 173, 166-171. doi: 10.1016/j.vetmic.2014.07.009

Mudrak, B., and Kuehn, M. J. (2010). Heat-labile enterotoxin: beyond G(m1) binding. Toxins (Basel). 2, 1445-1470. doi: 10.3390/toxins 2061445

Mudrak, B., Rodriguez, D. L., and Kuehn, M. J. (2009). Residues of heatlabile enterotoxin involved in bacterial cell surface binding. J. Bacteriol. 191, 2917-2925. doi: 10.1128/JB.01622-08

Nagy, B., and Fekete, P. Z. (2005). Enterotoxigenic Escherichia coli in veterinary medicine. Int. J. Med. Microbiol. 295, 443-454. doi: 10.1016/j.ijmm.2005.07.003

Nandre, R. M., and Lee, J. H. (2014). Generation of a safe Salmonella gallinarum vaccine candidate that secretes an adjuvant protein with immunogenicity and protective efficacy against fowl typhoid. Avian Pathol. 43, 164-171. doi: 10.1080/03079457.2014.897682

Nandre, R. M., Ruan, X., Duan, Q., Sack, D. A., and Zhang, W. (2016). Antibodies derived from an enterotoxigenic Escherichia coli (ETEC) adhesin tip MEFA (multiepitope fusion antigen) against adherence of nine ETEC adhesins: CFA/I, CS1, CS2, CS3, CS4, CS5, CS6, CS21 and EtpA. Vaccine 34, 3620-3625. doi: $10.1016 /$ j.vaccine.2016.04.003

Nashar, T. O., Betteridge, Z. E., and Mitchell, R. N. (2001). Evidence for a role of ganglioside GM1 in antigen presentation: binding enhances presentation of Escherichia coli enterotoxin B subunit (EtxB) to CD4(+) T cells. Int. Immunol. 13, 541-551. doi: 10.1093/intimm/13.4.541

Nawar, H. F., Greene, C. J., Lee, C. H., Mandell, L. M., Hajishengallis, G., and Connell, T. D. (2011). LT-IIc, a new member of the type II heatlabile enterotoxin family, exhibits potent immunomodulatory properties that are different from those induced by LT-IIa or LT-IIb. Vaccine 29, 721-727. doi: 10.1016/j.vaccine.2010.11.020

Nawar, H. F., King-Lyons, N. D., Hu, J. C., Pasek, R. C., and Connell, T. D. (2010). LT-IIc, a new member of the type II heat-labile enterotoxin family encoded by an Escherichia coli strain obtained from a nonmammalian host. Infect. Immun. 78, 4705-4713. doi: 10.1128/IAI.00730-10

Norton, E. B., Bauer, D. L., Weldon, W. C., Oberste, M. S., Lawson, L. B., and Clements, J. D. (2015). The novel adjuvant dmLT promotes dose sparing, mucosal immunity and longevity of antibody responses to the inactivated polio vaccine in a murine model. Vaccine 33, 1909-1915. doi: 10.1016/j.vaccine.2015.02.069

Norton, E. B., Lawson, L. B., Freytag, L. C., and Clements, J. D. (2011). Characterization of a mutant Escherichia coli heat-labile toxin, LT(R192G/L211A), as a safe and effective oral adjuvant. Clin. Vaccine Immunol. 18, 546-551. doi: 10.1128/CVI.00538-10

Norton, E. B., Lawson, L. B., Mahdi, Z., Freytag, L. C., and Clements, J. D. (2012). The A subunit of Escherichia coli heat-labile enterotoxin functions as a mucosal adjuvant and promotes IgG2a, IgA, and Th17 responses to vaccine antigens. Infect. Immun. 80, 2426-2435. doi: 10.1128/IAI.00181-12

Okamoto, K., Okamoto, K., Miyama, A., Tsuji, T., Honda, T., and Miwatani, T. (1988). Effect of substitution of glycine for arginine at position 146 of the A1 subunit on biological activity of Escherichia coli heat-labile enterotoxin. J. Bacteriol. 170, 2208-2211. doi: 10.1128/jb.170.5.2208-2211.1988

Petrovska, L., Lopes, L., Simmons, C. P., Pizza, M., Dougan, G., and Chain, B. M. (2003). Modulation of dendritic cell endocytosis and antigen processing pathways by Escherichia coli heat-labile enterotoxin and mutant derivatives. Vaccine 21, 1445-1454. doi: 10.1016/S0264-410X(02)00696-5

Pickett, C. L., Twiddy, E. M., Belisle, B. W., and Holmes, R. K. (1986). Cloning of genes that encode a new heat-labile enterotoxin of Escherichia coli. J. Bacteriol. 165, 348-352. doi: 10.1128/jb.165.2.348-352.1986

Pitcovski, J., Bazak, Z., Wasserman, E., Elias, O., Levy, A., Peretz, T., et al. (2006). Heat labile enterotoxin of $E$. coli: a potential adjuvant for transcutaneous cancer immunotherapy. Vaccine 24, 636-643. doi: 10.1016/j.vaccine.2005.08.052

Pizza, M., Fontana, M. R., Giuliani, M. M., Domenighini, M., Magagnoli, C., Giannelli, V., et al. (1994). A genetically detoxified derivative of heat-labile Escherichia coli enterotoxin induces neutralizing antibodies against the A subunit. J. Exp. Med. 180, 2147-2153. doi: 10.1084/jem.180.6.2147
Pizza, M., Giuliani, M. M., Fontana, M. R., Monaci, E., Douce, G., Dougan, G., et al. (2001). Mucosal vaccines: non toxic derivatives of LT and CT as mucosal adjuvants. Vaccine 19, 2534-2541. doi: 10.1016/S0264-410X(00)00553-3

Platts-Mills, J. A., Babji, S., Bodhidatta, L., Gratz, J., Haque, R., Havt, A., et al. (2015). Pathogen-specific burdens of community diarrhoea in developing countries: a multisite birth cohort study (MAL-ED). Lancet Glob. Health 3, e564-575. doi: 10.1016/S2214-109X(15)00151-5

Qi, Y., Kang, H., Zheng, X., Wang, H., Gao, Y., Yang, S., et al. (2015). Incorporation of membrane-anchored flagellin or Escherichia coli heat-labile enterotoxin B subunit enhances the immunogenicity of rabies virus-like particles in mice and dogs. Front. Microbiol. 6:169. doi: 10.3389/fmicb.2015.00169

Romero, J. F., Ciabattini, A., Guillaume, P., Frank, G., Ruggiero, P., Pettini, E., et al. (2009). Intranasal administration of the synthetic polypeptide from the C-terminus of the circumsporozoite protein of Plasmodium berghei with the modified heat-labile toxin of Escherichia coli (LTK63) induces a complete protection against malaria challenge. Vaccine 27, 1266-1271. doi: 10.1016/j.vaccine.2008.12.010

Roy, K., Hamilton, D. J., and Fleckenstein, J. M. (2012). Cooperative role of antibodies against heat-labile toxin and the EtpA Adhesin in preventing toxin delivery and intestinal colonization by enterotoxigenic Escherichia coli. Clin. Vaccine Immunol. 19, 1603-1608. doi: 10.1128/CVI.00351-12

Roy, K., Kansal, R., Bartels, S. R., Hamilton, D. J., Shaaban, S., and Fleckenstein, J. M. (2011). Adhesin degradation accelerates delivery of heat-labile toxin by enterotoxigenic Escherichia coli. J. Biol. Chem. 286, 29771-29779. doi: 10.1074/jbc.M111.251546

Ruan, X., Sack, D. A., and Zhang, W. (2015). Genetic fusions of a CFA/I/II/IV MEFA (multiepitope fusion antigen) and a toxoid fusion of heat-stable toxin (STa) and heat-labile toxin (LT) of enterotoxigenic Escherichia coli (ETEC) retain broad anti-CFA and antitoxin antigenicity. PLOS ONE 10:e0121623. doi: 10.1371 /journal.pone. 0121623

Ruan, X., and Zhang, W. (2013). Oral immunization of a live attenuated Escherichia coli strain expressing a holotoxin-structured adhesin-toxoid fusion (1FaeGFedF-LTA(2):5LTB) protected young pigs against enterotoxigenic E. coli (ETEC) infection. Vaccine 31, 1458-1463. doi: 10.1016/j.vaccine.2013.01.030

Ryan, E. J., McNeela, E., Pizza, M., Rappuoli, R., O'Neill, L., and Mills, K. H. (2000). Modulation of innate and acquired immune responses by Escherichia coli heat-labile toxin: distinct pro- and anti-inflammatory effects of the nontoxic AB complex and the enzyme activity. J. Immunol. 165, 5750-5759. doi: 10.4049/jimmunol.165.10.5750

Santiago-Mateo, K., Zhao, M., Lin, J., Zhang, W., and Francis, D. H. (2012). Avirulent K88 (F4) + Escherichia coli strains constructed to express modified enterotoxins protect young piglets from challenge with a virulent enterotoxigenic Escherichia coli strain that expresses the same adhesion and enterotoxins. Vet. Microbiol. 159, 337-342. doi: 10.1016/j.vetmic.2012. 03.046

Sjökvist Ottsjö, L., Flach, C. F., Clements, J., Holmgren, J., and Raghavan, S. (2013). A double mutant heat-labile toxin from Escherichia coli, LT(R192G/L211A), is an effective mucosal adjuvant for vaccination against Helicobacter pylori infection. Infect. Immun. 81, 1532-1540. doi: 10.1128/IAI.01407-12

Song, J. H., Nguyen, H. H., Cuburu, N., Horimoto, T., Ko, S. Y., Park, S. H., et al. (2008). Sublingual vaccination with influenza virus protects mice against lethal viral infection. Proc. Natl. Acad. Sci. U.S.A. 105, 1644-1649. doi: 10.1073/pnas.0708684105

Subramenium, G. A., Sabui, S., Marchant, J. S., Said, H. M., and Subramanian, V. S. (2019). Enterotoxigenic Escherichia coli heat labile enterotoxin inhibits intestinal ascorbic acid uptake via a cAMP-dependent NF-kappaBmediated pathway. Am. J. Physiol. Gastrointest. Liver Physiol. 316, G55-G63. doi: 10.1152/ajpgi.00259.2018

Sun, Z., Lawson, S., Langenhorst, R., McCormick, K. L., Brunick, C., Opriessnig, T., et al. (2013). Construction and immunogenicity evaluation of an epitopebased antigen against swine influenza A virus using Escherichia coli heatlabile toxin B subunit as a carrier-adjuvant. Vet. Microbiol. 164, 229-238. doi: 10.1016/j.vetmic.2013.02.010

Thiam, F., Charpilienne, A., Poncet, D., Kohli, E., and Basset, C. (2015). B subunits of cholera toxin and thermolabile enterotoxin of Escherichia coli have similar adjuvant effect as whole molecules on rotavirus $2 / 6$-VLP specific antibody responses and induce a Th17-like response after intrarectal immunization. Microb. Pathog. 89, 27-34. doi: 10.1016/j.micpath.2015.08.013 
Todoroff, J., Lemaire, M. M., Fillee, C., Jurion, F., Renauld, J. C., Huygen, K., et al. (2013). Mucosal and systemic immune responses to Mycobacterium tuberculosis antigen 85A following its co-delivery with CpG, MPLA or LTB to the lungs in mice. PLoS ONE 8:e63344. doi: 10.1371/journal.pone.0063344

Tsuji, T., Inoue, T., Miyama, A., Okamoto, K., Honda, T., and Miwatani, T. (1990). A single amino acid substitution in the A subunit of Escherichia coli enterotoxin results in a loss of its toxic activity. J. Biol. Chem. 265, 22520-22525.

Turcanu, V., Hirst, T. R., and Williams, N. A. (2002). Modulation of human monocytes by Escherichia coli heat-labile enterotoxin B-subunit; altered cytokine production and its functional consequences. Immunology 106, 316-325. doi: 10.1046/j.1365-2567.2002.01429.x

Verbrugghe, E., Van Parys, A., Leyman, B., Boyen, F., Arnouts, S., Lundberg, U., et al. (2015). Heat-labile enterotoxin of Escherichia coli promotes intestinal colonization of Salmonella enterica. Comp. Immunol. Microbiol. Infect. Dis. 43, 1-7. doi: 10.1016/j.cimid.2015.09.002

Viswanathan, V. K., Hodges, K., and Hecht, G. (2009). Enteric infection meets intestinal function: how bacterial pathogens cause diarrhoea. Nat. Rev. Microbiol. 7, 110-119. doi: 10.1038/nrmicro2053

Wang, X., Gao, X., and Hardwidge, P. R. (2012). Heat-labile enterotoxin-induced activation of NF-kappaB and MAPK pathways in intestinal epithelial cells impacts enterotoxigenic Escherichia coli (ETEC) adherence. Cell. Microbiol. 14, 1231-1241. doi: 10.1111/j.1462-5822.2012.01793.x

Wang, X., and Hardwidge, P. R. (2012). Enterotoxigenic Escherichia coli prevents host NF-kappaB activation by targeting IkappaBalpha polyubiquitination. Infect. Immun. 80, 4417-4425. doi: 10.1128/IAI.00809-12

Weltzin, R., Guy, B., Thomas, W. D. Jr., Giannasca, P. J., and Monath, T. P. (2000). Parenteral adjuvant activities of Escherichia coli heat-labile toxin and its B subunit for immunization of mice against gastric Helicobacter pylori infection. Infect. Immun. 68, 2775-2782. doi: 10.1128/IAI.68.5.2775-2782.2000

White, J. A., Blum, J. S., Hosken, N. A., Marshak, J. O., Duncan, L., Zhu, C., et al. (2014). Serum and mucosal antibody responses to inactivated polio vaccine after sublingual immunization using a thermoresponsive gel delivery system. Hum. Vaccin. Immunother. 10, 3611-3621. doi: 10.4161/hv.32253

World Health Organization (2006). Future directions for research on enterotoxigenic Escherichia coli vaccines for developing countries. Wkly. Epidemiol. Rec. 81, 97-104.

Yamamoto, M., McGhee, J. R., Hagiwara, Y., Otake, S., and Kiyono, H. (2001). Genetically manipulated bacterial toxin as a new generation mucosal adjuvant. Scand. J. Immunol. 53, 211-217. doi: 10.1046/j.1365-3083.2001.00883.x

Yu, L. C., Wang, J. T., Wei, S. C., and Ni, Y. H. (2012). Host-microbial interactions and regulation of intestinal epithelial barrier function: from physiology to pathology. World J. Gastrointest. Pathophysiol. 3, 27-43. doi: 10.4291/wjgp.v3.i1.27

Zhang, C., Knudsen, D. E., Liu, M., Robertson, D. C., Zhang, W., and STa Toxoid Vaccine Consortium Group. (2013). Toxicity and immunogenicity of enterotoxigenic Escherichia coli heat-labile and heat-stable toxoid fusion 3xSTa(A14Q)-LT(S63K/R192G/L211A) in a murine model. PLoS ONE 8:e77386. doi: 10.1371/journal.pone.0077386

Zhang, G. G., Li, D. X., Zhang, H. H., Zeng, Y. M., and Chen, L. (2009). Enhancement of mucosal immune response against the $\mathrm{M} 2 \mathrm{eHBc}+$ antigen in mice with the fusion expression products of LTB and M2eHBc+ through mucosal immunization route. Vet. Res. Commun. 33, 735-747. doi: 10.1007/s11259-009-9222-7

Zhang, W., Berberov, E. M., Freeling, J., He, D., Moxley, R. A., and Francis, D. H. (2006). Significance of heat-stable and heat-labile enterotoxins in porcine colibacillosis in an additive model for pathogenicity studies. Infect. Immun. 74, 3107-3114. doi: 10.1128/IAI.01338-05

Zhang, W., Zhang, C., Francis, D. H., Fang, Y., Knudsen, D., Nataro, J. P., et al. (2010). Genetic fusions of heat-labile (LT) and heat-stable (ST) toxoids of porcine enterotoxigenic Escherichia coli elicit neutralizing anti-LT and anti-STa antibodies. Infect. Immun. 78, 316-325. doi: 10.1128/IAI.00497-09

Zhang, W., Zhao, M., Ruesch, L., Omot, A., and Francis, D. (2007). Prevalence of virulence genes in Escherichia coli strains recently isolated from young pigs with diarrhea in the US. Vet. Microbiol. 123, 145-152. doi: 10.1016/j.vetmic.2007.02.018

Zoeteweij, J. P., Epperson, D. E., Porter, J. D., Zhang, C. X., Frolova, O. Y., Constantinides, A. P., et al. (2006). GM1 binding-deficient exotoxin is a potent noninflammatory broad spectrum intradermal immunoadjuvant. J. Immunol. 177, 1197-1207. doi: 10.4049/jimmunol.177. 2.1197

Conflict of Interest Statement: The authors declare that the research was conducted in the absence of any commercial or financial relationships that could be construed as a potential conflict of interest.

Copyright (c) 2019 Duan, Xia, Nandre, Zhang and Zhu. This is an open-access article distributed under the terms of the Creative Commons Attribution License (CC BY). The use, distribution or reproduction in other forums is permitted, provided the original author(s) and the copyright owner(s) are credited and that the original publication in this journal is cited, in accordance with accepted academic practice. No use, distribution or reproduction is permitted which does not comply with these terms. 